\title{
Thermodynamics of the Technosphere: Rethinking Temporality and Technicity in the Age of Planetary Emergency with Heidegger and Stiegler
}

\author{
PIETER LEMMENS \\ FACULTY OF SCIENCE \\ INSTITUTE FOR SCIENCE IN \\ SOCIETY \\ RADBOUD UNIVERSITY NIJMEGEN, \\ THE NETHERLANDS
}

\begin{abstract}
This article critically reflects on Stiegler's reinterpretation of Heidegger's views on the relationships between existential temporality, understanding of being and technology within the context of the latter's notion of enframing, reconceptualized as an explicitly planetary phenomenon: the technosphere. Stiegler replaces Heidegger's ontological conception with an organological one, arguing that the latter fails to understand these phenomena from the crucial perspective of thermodynamics, i.e., of the question of entropy and negentropy, which has never been addressed by Heidegger. What I particularly aim to show is that Stiegler's organological re-intepretation of enframing as the technosphere and of existential temporality in terms of 'quasi-causality' (per Deleuze) may profit from being put in the broader, geothermodynamic context of Earth System Science and considered from the perspective of Schneider \& Sagan's 'gradient theory', i.e., as being driven by what may be called the planetary 'thermodynamic imperative' with Jeffrey Wicken.
\end{abstract}




\section{INTRODUCTION}

The question of time, i.e., of human temporality in its relation to technology, is probably the core question of the philosophical project of Bernard Stiegler ${ }^{1}$. In his unfinished magnum opus Technics and Time, Stiegler basically aims to elucidate the fundamental role of technical artefacts in the constitution of the temporal structure of human subjectivity and existence. He does so through a dialogue, principally, with (1) Husserl's transcendental analysis of internal time consciousness, explained in terms of retentionality and protentionality and with (2) Heidegger's existential analytic of the ecstatic-horizontal temporality and historicity of Dasein, characterized by thrownness and projection.

Since the turn of the century Stiegler started to re-think existential ontology and its temporal structure in terms of an existential organology and that is to say: a theory of the changing configurations of three organs or organ systems that interact and co-evolve transductively (i.e., reciprocally constituting themselves through their evolving relation): psychic organs, collective organs (or social organizations) and technical organs (or technical artefacts and systems).

The temporality of the first two organ systems (i.e., psyches and collectives), which consist of what Husserl called primary and secondary retentions and protentions, is ultimately conditioned by what Stiegler calls the third or technical organ system, which consist of tertiary ( $=$ artificial) retentions and increasingly also protentions (Hui). These have become principally digital, networked and automatized today, on a global, planetary scale. In addition they are overwhelmingly annexed and exploited by a fully computationalized capitalist economy bent on maximizing consumption, for the sole purpose of accelerating the speed of returns on investment.

Operating incessantly and almost at the speed of light, capitalist controlled digital

\footnotetext{
${ }^{1}$ Stiegler sadly died after I wrote this article, on the 6th of August 2020, at the age of 68. His death represents an incredible loss for philosophy.
}

infrastructures are thus in the process of short-circuiting as well as outstripping and overtaking the temporalities of individual and collective existences. This effectively annuls the primary and secondary retentions and protentions of these existences, thereby systematically ruining their noetic capacities (Stiegler, Automatic Ch. 4).

We are now facing the real danger of a generalized automatization of existences (Automatic 19). And this confronts us with the increasingly apparent impossibility today, Stiegler contends, of continuing human civilization in the future as a rational and autonomous endeavor. Their existence being conditioned fundamentally by technology, humans are called to continuously transform the process of technological development or technical becoming [de-venir] that pervades them into a genuine collective future [a-venir], so as to create a life worth living (Stiegler, Cinematic time 7). Today's pervasive automatizaton of all facets of life though puts this possibility in jeopardy and this is becoming even more urgent today in the context of what is called the Anthropocene, the new geological period in which the anthropic technosphere is threatening to destroy the very biosphere that constitutes the ultimate life support system of the anthropos.

Within this new horizon of planetary emergency, Stiegler has started to reemphasize his interpretation of human and technical temporality in terms of entropy and negentropy, notions originally derived from thermodynamics but interpreted in a more broad sense to include vital as well as libidinal (i.e., anthropic) energy.

In this article I want to focus briefly on Stiegler's re-interpretation of technicity, temporality and noeticity in the language of entropy and negentropy. And I will do so against the backdrop of Heidegger's later analysis of technology as enframing [Gestel] and then attempt to situate it within the broader context of Earth System Science (henceforth ESS) and geothermodynamics, 
in particular as conceived by the so-called gradient theory of Eric D. Schneider and Dorion Sagan.

\section{TEMPORALITY, TECHNICITY AND ORGANOLOGY}

What should be mentioned in the first place here is that Stiegler understands technical artefacts ultimately as artificial memory traces or retentions. And it is from this retentional understanding of technics that his whole conception of temporality can be understood. One of the key concepts in his work, as already indicated above, is that of the tertiary or technical retention, a concept he developed through a reading of Husserl's Lectures on the 'Phenomenology of Internal Time Consciousness'.

Stiegler demonstrates with respect to Husserl that the retentional-protential structure of internal time consciousness, thought of in terms of primary and secondary retentions and protentions, is fundamentally conditioned by these tertiary retentions or memories. Vis-à-vis Heidegger he shows in a similar fashion that the ecstatic-horizontal structure of existence can only be conceived of on the basis of these tertiary retentions. Heidegger touches upon these when he discusses the 'world-historial' (i.e., objects bequeathed from the past) but dismisses them as being without significance for thinking about Dasein's originary temporal structure (Stiegler, Disorientation 4-7).

In the first volume of Technics and Time Stiegler rethinks Heidegger's existentialand onto-historical understanding of human temporality and historicity as proceeding from a dynamic transductive relation between an advancing process of technical individuation, as a process of becoming [devenir], and a principally 'responsive', either adoptive or adaptive process of psychic and collective individuation, as a process of 'futuring' or the projection of a future [avenir]. $\mathrm{He}$ thereby interprets what Heidegger understood in a transcendentalist, purely

\footnotetext{
2 I.e., the organized organic beings or biological organisms that humans also always remain for Stiegler (in contrast to Heidegger.
}

ontological sense and with an emphatic neglect of the biological substructure, as an organological interplay between psychic organs ${ }^{2}$, the collective organs, and the technical organs as the organized inorganic beings with which humans are originally and intimately coupled. This coupling is not organic but indeed organo-logical, as the technical organs do not intrinsically belong to the human organism. They are organized yet inorganic ('dead') and this goes a long way in explaining why Stiegler considers them fundamentally as pharmaka which can both elevate or intensify and thwart or even destroy the potentials of the psychic and collective organs (Stiegler, For a New Critique 42).

With his organo-logical understanding of Heidegger's strictly onto-logical and later onto-historical approach to human existence and its temporal structure, Stiegler rethinks the latter's existential ontology in terms of what might be called 'techno-organicity'. Contrary to Heidegger, and more in agreement with the Marx and Engels of the German Ideology, Stiegler embraces with this techno-organic reinterpretation of Dasein reinterpreted with Canguilhem as a technical or technicized lifeform - a thoroughly materialist perspective. This is a perspective that Heidegger always resisted, apparent for instance from his frequent remarks about technology being in essence something 'spiritual' [geistig] (Heidegger, Hölderlin's 'The Ister" 53) ${ }^{3}$. While Heidegger rejected the idea that human existence may be understood from an organic-organismic perspective at all, Stiegler's organology explicitly assumes it and tries to understand existential temporality from the transductive dynamic resulting from the negotiation, as it were, between human biology as the organized organic and technology as the organized inorganic (Stiegler, Fault of Epimetheus 17). And Heidegger's 'history of being' is therefore conceived in terms of an ontogenesis, proceeding from an artefactual organogenesis which is itself rooted in a process of technical

\footnotetext{
${ }^{3}$ By which he meant that it was ultimately a way of knowing and thinking rooted in a certain disclosure of being preceding any concrete technical fabrication.
} 
exteriorization or what Stiegler lately has come to call exosomatization with a term from the Polish-American biologist Alfred Lotka (Stiegler, Neganthropocene 77).

In contrast to Heidegger, who denied any constitutive status to both the organic and the technological in his understanding of existence to locate its abyssal foundation fully in what he called 'Being', Stiegler apprehends it from an original coupling of the organic and the organized inorganic that technology is. He thereby conceives of 'Being', one could say, as that which unfolds as the way in which this coupling is being negotiated, questioned, reflected upon, etc. While Heidegger sees Being as the ultimate ground to which human existence 'indestructibly belongs' (cf. Heidegger, The Question 32) despite insistently forgetting it, Stiegler contends that what is ultimately constitutive for human existence and cannot be reduced to something more original is its exosomatic or technical condition. This condition rooted in humanity's original default of origin, of which it can never be cured but of which it can and must take care of (Neganthropocene 249).

Moreover, for Stiegler the beingplaced-into-question of human existence by technology, i.e., by the technical pharmakoninducing the pharmacological shock or disruption - is older and more original than this existence's possibility of questioning both its own being and that of other beings and the world, which would be the authentic enacting of its future. The pharmakon as the human's inorganic 'pros-thetic pro-jection', as Stiegler explains, is necessarily 'pre-ceding its possibility of posing questions', doing so 'as a kind of inorganic drive, that is, as an essentially automatic situation' (Stiegler, What Makes Life 108). But this 'inorganic drive' that is the pharmakon can also, and especially given its toxic functioning in the current context of cognitive and consumerist capitalism, block or obstruct this questioning, to the point of automatizing human existence itself and thereby dissolving its future within its technical becoming. Contrary to Heidegger or so it seems, Stiegler holds that Dasein's 'belongingness to Being' is not indestructible since it hinges on the adoptive appropriation of the pharmakon.

\section{ORGANOLOGY OF ENTROPY AND NEGENTROPY}

The current digital retentions or technical organs, in the form of digital automation, big data, ubiquitous computing, artificial intelligence, machine learning, algorithmic governmentality, etc., by shortcircuiting psychic and collective individuation processes, represent the threat, also for Stiegler, of a final closure of any genuine openness to the future Heidegger called the danger of technology. Yet, instead of understanding this danger in a purely ontological or onto-historical sense, as Heidegger did, he aims to rethink it from an organological perspective and he does so very explicitly since 2014 through the notions of entropy and negentropy (see explanation below). In the context of his thinking of the human condition as a technical condition Stiegler has coined the terms anthropy and neganthropy, which are bascially the anthropic, i.e., techno-organic modifications of these two notions, referring to the entropy and negentropy produced organologically (Neganthropocene 40).

What this means, if I'm correct, and this is what I want to focus attention on, is that the whole of the existential analytic as well as the history of being as phenomena of temporalization must be understood in Stiegler's view within a domain from which Heidegger wanted to exclude it radically from the very beginning, and that is the domain of 'the effectual' [das Wirksame] or 'effectiveness' [Wirksambeit], which is to say: of causality (Heidegger, Insight 39). However, Stiegler proposes to rethink the existential temporality of Dasein as well as the onto-alaletheialogical dynamic Heidegger referred to as the revealing of beings, in terms of what he calls, with a notion derived from the early Deleuze, quasi-causality (What Makes Life 24).

The operation of quasi-causality would precisely represent the creative and inventive adoption of technical becoming as a fundamentally entropic process so as to turn it, by therapeutically reversing it from a 
poison into a medicine, into a neganthropic and negentropic future by making it the basis of new capacities and faculties of thinking, new modes of being and new forms of questioning and knowledge generation, in short a new noetic and libidinal regime and a new orientation of human existence.

Thinking organologically rather than ontologically or onto-historically and conceiving human existence materialistically in terms of a dynamic transductive relation of co-individuating organic and inorganic beings, Stiegler insists on the technicalontical condition of all Dasein and must therefore explain the emergence of human temporality - or the 'enactment' of what Heidegger called the ontological difference as resulting from, if we may call it like that, a certain 'operation' of technicity upon organicity. And this is where the questions of entropy and negentropy and that of anthropy and neganthropy become crucial. Stiegler reproaches Heidegger for having neglected this question but Heidegger would probably respond by accusing Stiegler of persisting in a technical interpretation of both being and thinking. This 'operation', which turns the entropic becoming of technicity into a negentropic future of Dasein, is that of quasicausality and I will come back tot this.

But first, how does Stiegler understand these terms and what do they teach us concerning his view of the relation between technology and temporality? Briefly put: entropy is the universal tendency of the physical cosmos toward increasing disorder and decay, prescribed by the famous second law of thermodynamics. Negentropy or antientropy, as it was introduced by the Austrian physicist Erwin Schrödinger in his influential 1944 book What is Life?, refers to the local countertendency - so far only observed on Earth - of living organisms to increase order and complexity and to resist, i.e., defer, their own inevitable entropic decomposition, which would be death. This process of deferral precisely constitutes the temporality of organisms, i.e., of life or the organic, which Stiegler understands with Simondon as a process of vital individuation and with Derrida as a process of vital (or genetic) differentiation, as the (auto-)production of vital differance. This process, as he puts it, operates through 'negentropic organogenesis' (Neganthropocene, 80), which Aristotle - ignorant of course of the second law - thought with the notion of physis, understood as the 'bringing-forth' [poiesis] which has its 'outburst' in itself, being 'auto-poietic' we could say.

Anthropy and neganthropy are the neologisms Stiegler proposes for the struggle against entropy of buman organisms, understood as psycho-social processes of individuation that not only differentiate vitally but also and most importantly technically, and that means for Stiegler - who thinks that all noesis is at bottom a technesis noetically (Stiegler, Automatic 201). And also libidinally, through long circuits of desire and not via instinctual circuits, as in organic life. This technical-noetic differentiation proceeds by way of exosomatization and as a process of artificial or inorganic organogenesis or organization it is deeply pharmacological. It produces both anthropy and neganthropy as well as both entropy and negentropy.

The whole 'point' of the human technical adventure, as becomes obvious and urgent in the age of the Anthropocene, is to maximize the neganthropic and negentropic and to minimize the anthropic and entropic effects of this process through and adoptivcreative appropriation of the process of exosomatization and seizing it as an instrument for producing noetic différance, which is to say knowledge in all its forms - and for creating circuits of individual and collective desire, e.g., the desire to know, to attend and to care.

\section{NEGENTROPY, NOESIS AND QUASI CAUSALITY}

Aristotle referred to the process of exosomatization as techne and opposed it to physis as a 'bringing-forth' [poiesis] that had its 'outburst' not in itself but in another, the craftsman or artist; it being allo-poietic. We know that Heidegger turned to Aristotle's theory of the four causes in his questioning of the essence of technology. Though I cannot go into all the intricate details of his interpretation of this theory here, one of the 
crucial points he made is that the so called efficient cause, in the sense in which it is known and indeed acknowledged as practically the only genuine cause in modern science and technology, was in fact unknown to Aristotle and to the Greeks in general. The latter understood this cause of the 'origin of change and rest' not in the causal sense of effecting it but in the noetic sense of pondering it, considering it or reflecting upon the process and thus of gathering the other three causes in a certain way, i.e., in the sense of logos or legein (The Question 8).

It is at this point that Heidegger proclaims that all bringing-forth is in essence a 'bringing out of concealment into unconcealment', and puts forward his famous thesis that technology is a mode of revealing, what the Greeks called aletheuein, thereby linking technology to truth, i.e., to the truth of being (The Question 13). He then goes on to show that modern technology is in its aletheic essence not so much a bringingforth but a 'challenging-forth', the overall legein or gathering essence of which he indeed designated as enframing, conceived of as an imperative or claim coming from Being which gathers humans toward revealing beings as standing reserve (The Question 17).

Stiegler largely concurs with this analysis. Contrary to Heidegger though, who represses in his view the priority - 'ontically' - of the process of exosomatization as the production of pharmaka and instead prioritizes Being as the purely ontological origin of all exosomatization, Stiegler is forced from his organological viewpoint to rethink the causal explanation of technology as a mode of bringing-forth and of revealing put forward by Aristotle. What critically distinguishes his view from Heidegger's, who remains within metaphysics in this sense, is that he acknowledges a form of 'selfcausality' animating technical beings, an advancing dynamic properly belonging to these inorganic organized beings. This is precisely the process of technical exteriorization as the quasi-autonomous process of technical becoming or what the French paleoanthropologist André Leroi-
Gourhan has called the technical tendency (Fault of Epimetheus 17, 36).

It is this insight that compels him to re-interpret Aristotle's well-known four causes-explanation in a fundamentally different way than Heidegger did. And the whole issue, as far as I can see, revolves around the question of how to think final causality within or more properly: beyond this scheme. Aristotle and the whole of the metaphysical tradition situated the final cause along with the efficient and the formal causes in the craftsman or the producer, which Stiegler also calls the operator, and which more generally may be called the subject or also the agent. Heidegger though, I would suggest, situated the final cause in Being as physis and as aletheia which, as he insisted, is never something made by humans' (The Question 18).

Stiegler, for whom human existence or subjectivity originates from the accident of technology rather than Being, attempts to rethink final causality organologically from the transductive relation between the human and technology. And he does so by replacing Aristotle's theory of four causes with the thought of quasi-causality. He considers this to be not so much a theory but an experience, the experience of an ordeal (Stiegler, Nanjing 73), the ordeal of having to deal with the insurmountable technical condition. This is the condition of being constantly challenged and put into question by a process of exosomatization that incessantly traverses the human. It is a process that the human vitally relies upon for its possibility to exist and to project itself into a future, i.e., to consist. Yet it can also always block and undermine this possibility, impossibilize it so to speak, thus making existence tendentially regress toward sheer subsistence.

Now this quasi-causality is a very difficult notion and I do not claim to fully understand it. What it amounts to as far as I'm concerned is an attempt to think in a completely new, explicitly materialist sense, and thereby also reclaim the priority of, final causality, which has been totally eliminated within modern technoscientific reductionism (and which is the mark of its nihilism). 
Stiegler conceives of quasi-causality as the way in which humans fully assume and adopt the inevitably and insurmountably toxic-entropic, i.e., pathogenic and disruptive process of technical becoming, which today is the global process of digitalization overwhelming humankind as a colossal and ever accelerating automaton. And this means: facing and living up to its traumatic truth as it were, willingly becoming its patients and then therapeutically taking care of it, by granting it the highest 'question-worthyness' or Fragwürdigkeit to put it with Heidegger, and thereby turning it into the basis of a negentropic and neganthropic temporality of new collective protentions or in other words new desires - a new existential future in short, breaking with the contemporary absence of futurity or the No Future foreseen already by the 'Punks' in the late 1970s.

In the most practical sense it would involve the quasi-causal reversal of today's disempowering and de-autonomizing force of automatization, which increasingly reduces our lives to servicing efficiency, into a power to dis-automatize and that is to say to 'gain time' not for profit accumulation but for thinking, questioning, reflecting and a rekindling of the collective imagination, i.e., for producing neganthropy or noetic différance (Neganthropoce 94).

Heidegger would have talked in this sense about an 'other commencement' and an 'other thinking', about a reciprocal 'turn' in being and thinking, expecting it to come not from the material facticity of digital technology (or cybernetics as he called it) but instead from another destining of Being which might dawn upon us on the condition that we stopped staring ourselves blind on digital artefacts and obeying the imperative of enframing, and started instead listening to the long-forgotten yet pristine call of being reverberating through it.

For Stiegler, convinced of the primacy of exosomatization above any relation to Being, the question is no longer Being or the ontological difference between Being and beings à la Heidegger, but the 'neganthropic (and exosomatic) différance between future [avenir] and becoming [devenir]' (Stiegler,
Disruption 304), i.e., the future understood as the quasi-causal realization of neganthropic, i.e., noetic 'bifurcations' in the process of entropic, i.e., automatic becoming [devenir] which techno-evolution as that which fundamentally conditions Dasein always is. For Stiegler, Dasein is the possibility of making 'becoming happen [fait advenir le devenir] as being, i.e., of what Nietzsche in the Will to Power described as 'imprinting on becoming the character of being' (What Makes Life, 133). So it is about Being, about the possibility of Dasein after all, yet understood in a new way as that which can only be insofar as it manages to 'surf, as it were, on the ambiguous, 'dangerous' yet also 'saving' waves of exosomatization.

\section{QUASI-CAUSALITY AND THE}

DANGER OF THE TECHNOSPHERE

In the age of what Heidegger called enframing and which Stiegler today associates with the Anthropocene interpreted as the Entropocene, this possibility is in serious jeopardy. To put it bluntly, what Heidegger called the danger and understood as the total forgetfulness of Being and the consequent implosion or closure of the ontological difference, Stiegler thinks as a pharmacological situation of generalized entropy and the consequent reign of denoeticization and proletarianization. And what Heidegger called the saving power and conceived of as the 'event of appropriation' in the sense of a turning toward a renewed exposure to Being, Stiegler interprets as the quasi-causal reversal, highly improbable that is, of this state of generalized entropization in the sense of a negentropic and neganthropic, pharmacological turn - and with it a new age of noesis which would inaugurate what he calls the Neganthropocene (Automatic 7).

Only through such a global bifurcation, a notion also deriving from thermodynamics, can we hope to survive and persist as the species that prides itself with having transcendend the pure animalistic struggle for survival. It would mean the birthing of that 'dancing star' evoked by Nietzsche in the preface to Thus Spoke Zarathustra, birthed by 
that new 'overman' which Stiegler calls the neganthropos.

Now, in his most recent writings about the (Neg)Anthropocene, interestingly, Stiegler has started to identify Heidegger's enframing with a notion that has lately been introduced within ESS as a purely geophysical concept and that is the technosphere (Nanjing 293). And it is clear that he understands this technosphere primarily as the noosphere, alhough he hardly uses this term $^{4}$. Considering his diagnosis of the current reign of denoeticization it can be argued though that with respect to the planetary crisis it incites, the noosphere is today still largely an 'ignoosphere' or 'ignorosphere', only in itself but not yet for itself (to use Hegelian terminology). To emphasize the profound connection between techne and noesis though, I prefer to talk about the technonoosphere.

Stiegler perceives the technosphere as an Earth-scale pharmakon and claims that it has come to replace the biosphere now, substituting techne for physis as the principal geodynamic factor. And it is of this Earthscale pharmakon that we must become the quasi-cause in the Anthropocene, so as to turn it into a negentropic-neganthropic engine again, and thus to produce the Neganthropocene. This would be the organologized version of what Heidegger called Ereignis, and probably also of what the latter termed the Geviert (Fourfold). But we are very, very far away here, for sure, from Heidegger's understanding of inhabiting and sparing the Geviert as a released and quiet 'poetically dwelling' on the Earth and under the heavens (Basic Writings 352), and this gives a lot to ponder upon, but I won't do that here.

But what does this all have to do with the relation between technology and temporality? Quite a lot. For Stiegler, who also relies in this context on Whitehead's

4 This notion was coined by Pierre Teilhard de Chardin and taken up later by Vladimir Vernadsky, who referred with it to the impact of human thought or reason, concretely through science and technology, on the Earth. understanding of the 'function of reason' as the power to bifurcate ${ }^{5}$, the noetic represents the possibility, albeit a very improbable one, of inducing, with infinite speed and that is to say through desire as the power to infinitize, neganthropic and negentropic detours or deferrals within the temporalities of human existence. For Stiegler this means within the processes of psychic and social individuation as conditioned by technical individuation (Neganthropocene 41).

The noetic is here understood in a deep relation to time, or better as time, and from its profound entanglement with technology, i.e., organologically, in a completely new sense, one that is rather different to be sure from the 'other thinking' prophesized by Heidegger, namely as the quasi-causal 'power to create bifurcations within entropy' (Neganthropocene 60). And this takes place as a process embedded within, yet increasingly aslo co-determining - as technosphere -, the overarching energetic totality that is the Earth system.

Nevertheless it should be recognized that this process will always remain ultimately bound by the Earth system - indeed earthbound as Bruno Latour would have it (Latour 2017, 38). And this means that it is a bit premature to claim that the technosphere has replaced the biosphere, as Stiegler does (Neganthropocene 335). The former is still fully dependent on the latter, as well as on the other geospheres and if it does not find a way to recycle its massive wastes, indeed its entropic production, it might soon disappear as a failed experiment as Earth system scientist Peter Haff points out (Haff, 4).

And here we should emphasize that the technosphere is the noosphere and vice versa. The future of the technosphere, which is our future, depends on the negentropic and neganthropic ingenuity of the anthropos overcoming itself technologically as the neganthropos. This will become increasingly

\footnotetext{
${ }^{5}$ And bifurcating means to effect radical breaks or turns in the automaticities and repetitive regularities of (technical) becoming by radically changing the rules (Neganthropocene 41).
} 
problematic now that the other geospheres start behaving in an ever more volatile, chaotic and unpredictabe way, acquiring ever more 'agency' as authors such as Michel Serres, Isabelle Stengers, Bruno Latour and Clive Hamilton emphasize.

\section{THE TECHNOSPHERE AND THE THERMODYNAMIC IMPERATIVE}

Such an understanding of the role of thinking is painfully tragic, much more tragic than the ancient Greeks as the originators of techne could have ever imagined. Yet it is the inescapable outcome of our technological bybris and it may also be understood as the most severe 'narcissistic offence' (Sloterdijk) humans ever had to swallow.

To get an even better grasp of what is truly at stake here at the level of the Earth system, and this will conclude my article, I want suggest we need to add another element to the picture that is not taken into account by Stiegler and that is the so-called 'gradient theory' proposed by Eric D. Schneider and Dorion Sagan in their 2005 book Into the Cool. The basic idea behind this theory, astonishingly simple in principle but complex in its theoretical elaboration, is that 'nature abhors a gradient'. We can describe this as the principle that all physical, chemical, vital, ecological, economic and also noetic processes can be see as so many ways of reducing differences across a distance, be it differences in temperature, energy, chemical concentration, pressure, or otherwise (Schneider \& Sagan 2005, 6).

The core of gradient theory is formed by the second law of thermodynamics, i.e., the law of entropy already mentioned, but what it shows is that instead of predicting the increase of disorder and ultimately the ominous 'heat death' of the universe, as did the classic $19^{\text {th }}$ century version, it actually explains the increase in complexification. It teaches us the counterintuitive fact that the more complex a system is, the more efficient

\footnotetext{
${ }^{6}$ This book builds on the work of Erwin Schrödinger, Alfred Lotka, Ilya Prigogine and Jeffrey Wicken among others and is based on so-called nonequilibrium thermodynamics.
}

it is in reducing gradients and thus increase the production of entropy, which is in obeyance with the second law and thus not against $\mathrm{it}^{7}$. Ultimately living organisms are not anti-entropic though, since it is precisely their extreme local complexity that makes them extremely efficient in producing global entropy.

What Schrödinger did not yet realize in the 1940s, and this is exactly what gradient theory adds to the picture, is that the negentropic tendency exhibited by living systems crucially feeds on the external, energy-rich organization of the gradients around them. And the ultimate gradient on which all of life feeds, and which explains both its emergence and evolution on our planet, is the giant radiation gradient between between the surface temperature of the Sun and the temperature of outer space, in which our planet is suspended and apparently so in what is called the Goldilocks zone in astrobiology.

Although it is impossble to enter into any detail, what is important to realize here is that this cosmic gradient provides a constant high-energy influx which, on Earth, has given the impetus - the 'go' as Jeffrey Wicken put it - for life both to originate and to persist (Schneider \& Sagan 2005, 105-6). And not only persist, it also explains life's complexifying tendency, as the increase in complexity increases the potential of living organisms and ecosystems to produce entropy (which means eliminating gradients). From this perspective, the original and most basic function of living organisms as well as the ecosystems which they form and through which they are formed, is to reduce ambient gradients. As evolution progressed, life has produced ever more efficient gradient reducing systems.

The emergence of intelligence can in this respect be seen as a means to further enhance gradient reduction, providing the knowledge and knowhow to identify, access

\footnotetext{
${ }^{7}$ As was still believed by Schrödinger when he put emphasis on the anti-entropic nature of life as a producer of negative entropy.
} 
and use more and more of the available gradients. Indeed, life's directedness, its purposiveness or inherent goal-directedness, and that implies its temporal, futureorientedness, also originates from what Wicken has theorized as the thermodynamic imperative of gradient reduction (Schneider \& Sagan 2005, 158). It may be argued that it is the driving dynamic behind what the Greeks called physis and what we now understand as the biosphere and that it also shines light on its overall finality in terms of biospheric complexification.

To finally return to the theme of technology and temporality: although Schneider and Sagan hardly ever talk about technology, we may surmise that the emergence of the technosphere as the process of exosomatization entering into its industrial and global phase is also driven in the last instance by the thermodynamic imperative. This certainly resonates with the way Haff describes the technosphere, namely as an emerging geothermodynamic process that has bootstrapped itself into existence while entraining humans as essential components. Haff also invokes the so-called 'principle of maximum entropy production' [PMEP], suggesting that the technosphere will tend toward increased appropriation of usable energy - which is to say: gradients - carrying its human parts along in the process (Haff 2013, 3-4). What is lacking in Haff though is a thoroughly organological understanding of the technosphere. His is a rather reified one and conceived as an autonomous process of which humans are considered to be just components or parts, essential yet also subordinate, not the default-driven transductive constituents Stiegler conceives of them.

At the same time we may ask to what extent the imperative of enframing analyzed by Heidegger as that challenging 'force' that claims human beings to disclose and exploit the Earth as a gigantic energy reservoir may be related to the thermodynamic imperative? Enframing forces us, Heidegger wrote, to challenge forth the energies of nature as efficiently as possible - 'to the maximum yield at the minimum expense' (Insight, 15).
And when he remarked in the famous Spiegel interview from 1968 that through enframing man was challenged by a power he could not himself control, does it make sense here to associate this 'power' with the hidden pressure exercised by the imperative of gradient reduction, though not yet understood in terms of the necessity to create negentropic bifurcations in the sense of deferrals or detours in the process of technical becoming which tends toward entropy if it is not taken care of? Such deferrals or detours as trajectories of noetic and libidinal différance conditioned by technical différance are what allows for the constitution of existential futures, i.e., the time of openness, reflection and invention beyond pure calculation and efficiency so as to produce, always exosomatically, a new order of noetic, psychic, social and cultural diversity and indeed to resurrect a world.

And may we, by way of a conclusion, interpret Heidegger's saving turn toward or into the event of appropriation from this perspective as the realization by the anthropos of being held within the embrace of the thermodynamic imperative, embedded within yet also profoundly affecting, in the the Anthropocene, the thermodynamic flows of the Earth System. The anthropos, who is therefore destined to take care of them and thus assume responsibility for the biosphere and acquire response-ability through pharmacologically re-framing the technonoosphere from a toxifying and entropizing engine that closes off or even annihilates altogether the future, into a support structure for a new future. This new future would be a new temporality or history in which human and terrestrial time knowingly converge and in which we may hope to be surprised one day about what the technicized body of the Earth can do (Sloterdijk 2018, 20).

I must admit that it frequently dazzles me to consider Heidegger's profound reflections on the ultimately ontological essence of technology from this radically onticized and materialized organological, exosomatic and quasi-causal understanding opened up by Stiegler, and then trying to situate it within an earth-systemic and 
geothermodynamic perspective, which I've only just started to explore in this article.

It is obvious that Heidegger himself would absolutely reject this as the very opposite of what he had in mind and would instead think of it as a total surrender to enframing and the final sanction of the abandonment of being. Yet, we could also view it as the dawning, admittedly utterly tragic, of 'the innermost indestructible belongingness of man within granting' (Insight 32) - in 'das Gewährende', what grants things to endure, although we may be sure that it is not indestructible. However that may be, for Stiegler in any case the very possibility of a human future on this planet worth living depends on the full-scale negentropic and neganthropic metamorphosis, not overcoming, of the current techno-noosphere that has become its ineluctable condition.

\section{WORK}

\section{CITED}

Haff, Peter. 'Technology as a Geological Phenomenon. Implications for Human Well-Being'. Geological Society London Special Publications 395(1), 2013.

Heidegger, Martin. The Question Concerning Technology and Other Essays. Harper \& Row, 1977.

Heidegger, Martin. Basic Writings. Harper Collins, 1993.

Heidegger, Martin. Hölderlin's Hymn "The Ister". Indiana University Press, 1996.

Heidegger, Martin. Bremen and Freiburg Lectures: Insight into That Which is and Basic Principles of Thinking. Indiana University Press, 2012.

Hui. Yuk. On the Existence of Digital Objects. University of Minnesota Press, 2016.

Latour, Bruno. Facing Gaia. Eight Lectures on the New Climatic Regime. Polity, 2017.

Schneider, Eric D. \& Sagan, Dorion. Into the Cool. Energy Flow and the Thermodynamics of Life. University of Chicago Press, 2005.

Sloterdijk, Peter. What Happened in the Twentieth Century? Towards a Critique of Extremist Reason. Polity, 2018.

Stiegler, Bernard. Technics and Time 1. The Fault of Epimetheus. Stanford University Press, 1998.
Stiegler, Bernard. Technics and Time 2. Disorientation. Stanford University Press, 2009.

Stiegler, Bernard. For a New Critique of Political Economy. Polity, 2010.

Stiegler, Bernard. Technics and Time 3. Cinematic Time and the Question of Malaise. Stanford University Press, 2011.

Stiegler Bernard. What Makes Life Worth Living. On Pharmacology. Polity, 2013.

Stiegler, Bernard. Automatic Society Vol. 1. The Future of Work. Polity, 2016.

Stiegler, Bernard. The Age of Disruption. Technology and Madness in Computational Capitalism. Polity, 2019.

Stiegler, Bernard. The Nanjing Lectures 2016-2019. Open Humanities Press, 2020. 